\title{
SOBRE ALGUMAS TRANSFORMAÇÕES DA INDÚSTRIA CULTURAL NO BRASIL
}

\author{
On some transformations of the Culture Industry in Brazil
}

Sílvio Camargo'

\begin{abstract}
Resumo
Neste artigo busco analisar e refletir sociologicamente sobre aquilo que entendo ser um processo de transformação da indústria cultural no Brasil, que teria tido seu início a partir de meados da década de 1990, sendo que tais transformações teriam adotado maior visibilidade a partir dos anos 2000. Busco, desse modo, refletir em um estudo histórico e teórico sobre um período específico (2000 a 2005), recorrendo metodologicamente a uma comparação entre conceitos teóricos e realidade histórica, tomando como eixo prioritário de análise alguns aspectos específicos do cinema e da televisão brasileiras no período. Minha hipótese central é de que nesse período histórico a Indústria Cultural no Brasil passa a expressar um novo tipo de relação entre produção e consumo, indicando transformações quanto ao próprio conceito de indústria cultural, tal como originalmente proposto por Theodor W. Adorno e Max Horkheimer. 0 objetivo central do artigo é contribuir para uma atualização do conceito de indústria cultural diante de modificações substantivas no modo de produção capitalista, adotando a realidade brasileira como marco explicativo de tais transformações.
\end{abstract}

Palavras-chave: Indústria Cultural; produção cultural no Brasil; televisão; subjetividade.

\begin{abstract}
In this article, I intend to analyse and interpret what I consider to be a transformation process in culture industry in Brazil, in sociological terms. The transformation process would have started in the mid of the 1990s and a greater visibility at the beginning of the twenty-first century. Thus, I intend to investigate a specific period (2000 to 2005) through a historical and theoretical perspective. In the following I propose a methodological frame of comparison between theoretical concepts and historical reality, and it takes some specific aspects about Brazilian film production and television in that same period as a priority analysis axis. My central hypothesis is that the culture industry in Brazil presents a new kind of relation between production and consumption in that historical period. It indicates transformations in the concept of culture industry itself, such as originally proposed by Theodor W. Adorno and Max Horkheimer. The central goal of this article is to contribute to the discussion about the concept of culture industry before substantive alterations in the capitalist mode of production, and it takes the Brazilian reality as an explanatory mark of such transformations.
\end{abstract}

\footnotetext{
1 Professor do Departamento de Sociologia/IFCH da UNICAMP, Campinas, Brasil. E-mail: scccamargo@gmail.com.
} 
Keywords: Culture Industry; cultural production in Brazil; television; subjectivity.

I

Neste artigo $^{2}$ pretendo analisar e refletir, a partir do campo específico da sociologia e da teoria social, sobre as transformações da indústria cultural no Brasil no início dos anos 2000, propondo que deste momento em diante é possível identificarmos mudanças quanto à produção cultural no país, que aponta para uma tendencial importância da internet como a expressão tecnológica de um novo momento da história desta indústria cultural. Concomitante ao advento da internet no Brasil, o período entre 2000 a $2005^{3}$ também está marcado por outros processos, tais como a consolidação de novas formas de financiamento da produção cultural, e o advento de expressões culturais das periferias urbanas. Em tal cenário, em que as transformações tecnológicas formam um pano de fundo inquestionável, o modelo clássico da indústria cultural, usualmente exemplificado pelas indústrias do rádio, televisão e cinema, sofrem mutações, cujos impactos ainda estão em curso, mas trazem à tona problemas sociológicos também de natureza teórica, visto que, trata-se de um novo tipo de confronto entre o conceito de indústria cultural (HULLOTKENTOR, 2011) e a realidade social em transformação. Meu propósito é articular, ao mesmo tempo, um estudo histórico e teóricoepistemológico, como forma deliberada de apresentação de meus argumentos. 4

O que haveria de diferente entre a indústria cultural no Brasil dos anos 1970 para a indústria cultural dos anos 2000? Certamente, para

\footnotetext{
2 Agradeço aos bem formulados comentários do (a) parecerista anônimo, bem como à revisão textual realizada por minha orientanda Luisa Maria Rutka Dezopi.

3 O marco de surgimento da internet no Brasil é 1995 (CARVALHO, 2006). O recorte temporal (2000 a 2005) escolhido para este artigo se orienta pela hipótese de que transformações mais evidentes na produção cultural brasileira, relacionadas inclusive ao surgimento da internet, só são empiricamente visíveis a partir do início dos anos 2000.

4 Acerca da "forma de apresentação" deste artigo gostaria de esclarecer, primeiramente, que seu conteúdo resulta de um trabalho de pesquisa realizado entre os anos de 2015 e 2017. A alteração contínua no texto entre as dimensões histórico-empíricas e teóricas se deve ao fato de que nosso problema central é pensar o "conceito" de indústria cultural em dois tempos históricos distintos, tratando-se, assim, de teoria social e pesquisa empírica qualitativa em um mesmo processo de argumentação.
} 
usarmos linguagem marxiana, o avanço das forças produtivas efetivado na forma de transformações tecnológicas tem um papel significativo na configuração do novo cenário, ao mesmo tempo em que a singularidade de relações de produção sedimentadas por traços ideológicos peculiares de nosso capitalismo periférico. Entre o aparelho de "três em um", popular nos anos 1970, e os Smartphones/Iphones hoje acoplados à forma de vida de muitos milhões de pessoas, se estabelece uma diferença não apenas tecnológica e aprofundada em menos de quatro décadas, que nos possibilita lidar com novos modelos de audição, e de sensibilidade (TÜRCKE, 2010) onde há um conjunto de mudanças que não podem ser negligenciadas, notadamente quanto à relação entre produção e consumo cultural.

Ao tomar o ano de 1995 como marco de criação da internet no Brasil eu suponho, ao mesmo tempo, que o momento incipiente de sua popularização somente ocorreu a partir dos anos 2000.5 Momento de passagem do governo Fernando Henrique Cardoso ao primeiro governo Lula, de um novo tipo de relação entre produtores culturais e suas formas de financiamento, mas também de novidades nos cenários musical, televisivo e cinematográfico. Novidades que diziam respeito ao processo de produção de bens culturais nesses setores, ancorados em novidades tecnológicas de grande significado, dentre as quais a própria internet, mas igualmente quanto à forma estética apreensivel no que passou a ser produzido, isto é, novos elementos ideológicos se apresentaram em tal contexto cultural, expressando algumas transformações da própria sociedade brasileira, como por exemplo, a sua configuração de classes.

Tentarei aqui traçar um cenário preliminar da indústria cultural no Brasil, quanto aos seis primeiros anos da década de 2000, buscando

\footnotetext{
5 No início dos anos 2000 há um regular crescimento do uso da internet no Brasil. Até 2004, no entanto, o acesso à internet continua a ser predominante nas classes médias. A sua popularização se dá a partir deste ano com o advento do Orkut e a propagação de Lan Houses. Deve-se ainda considerar o advento da internet de banda larga, e as modificações do cenário econômico, que possibilitou o crescimento da aquisição de computadores por parcelas cada vez maiores da população (20 anos de internet no Brasil: FSP, 2016).
} 
ilustrações especificamente quanto aos ramos do cinema e da televisão, ${ }^{6}$ com maior ênfase nesta, como expressões adotadas como clássicas do conceito de indústria cultural, supondo que nos planos da produção e recepção de imagens encontremos pistas para a compreensão de um novo momento da relação entre economia e cultura, no rastro teórico das formulações de Fredric Jameson, por um lado, e por outro, na hipótese de que o capitalismo avançado, mesmo no cenário brasileiro, traz como uma de suas marcas um novo tipo de relação entre produtor e consumidor (CAMARGO, 2009), onde categorias clássicas implicadas no conceito de indústria cultural, como reificação e razão instrumental, se deparam, neste novo cenário, com a emergência de uma subjetividade socialmente apreensivel que desafia em parte o próprio conceito de indústria cultural tal como este foi originalmente formulado por Adorno e Horkheimer (1944 [1985]). ${ }^{7}$ Minha intenção central aqui não se expressa prioritariamente como crítica ideológica da forma, da dimensão estética dos bens culturais colocados em análise, mas na tentativa de apreensão das relações sociais implicadas na produção e circulação de tais bens culturais.

\section{II}

Os estudos sobre indústria cultural no Brasil jamais chegaram a ter uma grande repercussão no campo da Sociologia, tanto no que diz respeito à Teoria Social quanto à Sociologia da Cultura, ou mesmo à Sociologia da Comunicação. Cabe perguntarmos o porquê desta pouca importância, pergunta essa em parte também formulada por Maria Eduarda Rocha (2011). As restrições às teses de Adorno e Horkheimer

\footnotetext{
6 Tentarei dar ênfase à produção televisiva por ser este o ramo mais expressivo da indústria cultural brasileira desde os anos 1970 (ORTIZ, 1988; LASH \& LURY, 2007). Minha análise busca mobilizar argumentos que me parecem em certa medida escapar aos estudos do campo da comunicação, visto que, ao tomar a televisão brasileira como exemplificação empírica da hipótese apresentada, esta última tem como escopo fornecer elementos de reflexão teórica, no campo da teoria social contemporânea, quanto a um novo tipo de relação entre economia e cultura na sociedade contemporânea, conforme desenvolvido no livro Trabalho Imaterial $e$ Produção Cultural (CAMARGO: 2009).

7 A opção pelo caso brasileiro não se deve, necessariamente, a um entendimento de que nesse país haveria uma grande singularidade de sua indústria cultural ao ponto de diferenciá-la de outros países. Embora haja no Brasil certas peculiaridades, como, por exemplo, a importância da telenovela e da televisão aberta, meu objetivo é mostrar que as transformações globais que estão se processando no capitalismo mundial, quanto à relação entre economia e cultura, também aqui encontram solo de visualização empírica.
} 
sobre o conceito de indústria cultural estiveram presentes desde os anos 1970, quando seus textos começaram a ser traduzidos no Brasil, em um delineamento relativamente complexo de ideias e autores que se sobrepuseram aos autores da Dialética do Esclarecimento, mesmo no próprio âmbito dos estudiosos da Teoria Crítica. Walter Benjamin sempre desfrutou de alguma popularidade entre intelectuais brasileiros, principalmente no campo dos estudos literários, e a partir da década de 1980, Jürgen Habermas passou a ter uma proeminência no campo dos pesquisadores em Teoria Crítica, tanto entre filósofos como entre sociólogos (CAMARGO, 2012; 2014). E no que tange à Sociologia da Cultura em sentido mais amplo, os frankfurtianos ao longo das últimas três décadas foram crescentemente perdendo espaço para leituras mais próximas aos chamados Estudos Culturais, de origem britânica, bem como para a crescente influência de Pierre Bourdieu. Além disso, a maior parte das pesquisas e reflexões sobre indústria cultural no Brasil, que jamais foram muitas, em geral analisa um periodo histórico que vai até meados de 1990, momento que antecede ao surgimento, por exemplo, da internet no país.

É importante nos perguntarmos o porquê o conceito de indústria cultural no Brasil jamais ter tido grande repercussão na Sociologia e, ao mesmo tempo, pensarmos que ordem de críticas tal conceito se tornou alvo no campo dos debates sobre produção cultural. As razões para que poucos estudos sobre indústria cultural tenham se realizado no Brasil ao longo dos últimos quarenta anos são diversas. Apresentamos aqui três delas. Em primeiro lugar, o debate sobre indústria cultural possui um fundamento teórico essencialmente marxiano, na medida em que o seu fundamento teórico central é a noção de fetichismo da mercadoria, noção esta que conforme Roberto Schwarz jamais foi prioritária para os estudos sobre Marx no Brasil (SCHWARZ, 1998). No caso do campo específico do marxismo, e quanto às reflexões sobre cultura, este sempre esteve muito mais próximo de uma herança gramsciana do que de uma aceitação do legado frankfurtiano, para muitos pensadores sequer aceito como pertencente ao campo do marxismo. 
Em segundo lugar, o interesse inicial por estudos sobre indústria cultural que surgiu no início da década de 1970 já ao final daquela mesma década foi posto de lado, inclusive pelos próprios estudiosos da Teoria Crítica, tendo em vista que o emergente debate sobre a esfera pública, desde então até o presente, tende a invalidar a ideia de indústria cultural, enxergando nesta uma concepção de cultura assentada em uma visão unidimensional de racionalidade, não correspondente aos processos democráticos e deliberativos que teriam passado a caracterizar a sociedade brasileira desde a segunda metade dos anos 1980, inclusive quanto à esfera cultural (COSTA, 2002; AVRITZER e COSTA, 2004). Em terceiro lugar, cabe fazer uma muito breve digressão sobre outras tendências existentes no campo de debates sobre produção cultural no Brasil.

Em sentido oposto e crítico ao conceito de indústria cultural destacamos duas tendências: uma com forte presença no campo da chamada Sociologia da Cultura e outra mais próxima ao campo da comunicação. No que diz respeito à Sociologia da Cultura, já desde a década de 1970 a influência de Pierre Bourdieu na sociologia brasileira se tornou infinitamente mais significativa do que as de Adorno e Horkheimer, e isso no sentido da própria teoria social em sentido mais amplo. Para a vertente de estudiosos de Bourdieu, que considero hegemônica no campo da Sociologia da Cultura, os bens e artefatos culturais são tratados como bens simbólicos que expressam uma separação entre diferentes formas de poder e capital, onde uma forma de produção cultural, como por exemplo, a telenovela, não é analisada quanto ao seu conteúdo ideológico ou quanto ao seu processo de produção e circulação tendo em vista seu pertencimento a um modo de produção, como ocorre para o materialismo histórico e para as vertentes marxianas de análise da cultura. Para os bourdianos, um bem cultural é tratado prioritariamente quanto às suas dimensões de representação simbólica, que expressam as diferentes formas de distinção que demarcam a esfera cultural em uma determinada sociedade. Trata-se, comparando com a tradição frankfurtiana e no contexto da teoria social 
contemporânea, de um registro epistemológico completamente distinto daquele de Adorno e Horkheimer, onde o próprio conceito de indústria cultural deixa de ter sentido, pois tal conceito está ancorado em outra concepção de conhecimento e de ciência, visto que para os dialéticos da primeira geração da Escola Frankfurt o problema da cultura não é de natureza simbólica, mas sim de natureza material e histórica, ou para sermos mais claros, diz respeito fundamentalmente à relação entre consciência e realidade (COHN, 1990; 1998 a; 1998 b; CAMARGO, 2006; MAAR, 2000).

Outra tendência, que vê como completamente superada a noção de indústria cultural, mas desta vez mais visível entre os estudiosos da comunicação, tem recorrido a uma apropriação do pós-estruturalismo francês, principalmente Deleuze e Guattari, para destacar que o modelo industrial fordista deixou de existir desde a década de 1970, e em lugar dele tem emergido uma sociedade em que as redes, os fluxos e as multidões, no centro e na periferia, produzem cultura à margem ou em sentido crítico aos padrões hegemônicos do capitalismo, para os quais igualmente não caberia mais contemporaneamente falarmos de ideologia, e nem tampouco de uma produção cultural que estaria espelhada no velho modelo fordista, tal como ocorria com o conceito de indústria cultural cunhado nos anos $1940 .{ }^{8}$ Nesse mesmo sentido, de um modo geral os estudos que se originam das noções de cibercultura (LEVY, 1999; 2007), sociedade em rede (CASTELLS, 2003) e cultura digital, sequer fazem referência ao conceito de indústria cultural. Um bom exemplo é o livro Cultura Digital.br (COHN e SAVAZONI, 2009), uma coletânea de textos sobre cultura digital, de diversos autores, onde a expressão indústria cultural sequer aparece nos diferentes trabalhos ali escritos sobre cultura.

Para sintetizar o que diferencia os defensores do conceito de indústria cultural de seus críticos e opositores, e não só no Brasil,

\footnotetext{
8 Esta forma de interpretação predomina entre pesquisadores europeus a partir das publicações da revista francesa Multitudes. No Brasil esta forma de apropriação da ideia de cultura pode ser vista em inúmeros artigos publicados na revista Lugar Comum, vinculada à rede Universidade Nômade.
} 
entendo que a questão é fundamentalmente teórica quanto ao próprio conceito de indústria cultural: a ideia de indústria cultural está assentada em uma teoria da dominação (HONNETH, 1991), de inspiração marxiana, onde a questão central é o problema da consciência, tratada conforme a herança da dialética hegeliana, passando por Marx e Lukács, enquanto que seus opositores, desde pelo menos os anos 1970, tratam o problema da cultura mediante outros registros teórico sociais, ancorados em outras formas de postulação quanto ao próprio modo com que o conhecimento, o saber e a ciência são constituídos. O conceito de indústria cultural, em especial para Theodor W. Adorno, expressava mais do que a análise de bens culturais ou simbólicos, mas representava a maneira pela qual no chamado capitalismo tardio (ADORNO, 1986a) a dialética do esclarecimento encontrou a sua efetividade histórica no princípio da troca, fazendo com que os eventos singulares, incluindo aqueles que caracterizam o tempo livre dos indivíduos, só se tornem compreensíveis mediante a nossa capacidade de abstração de sua universalidade, trocando em miúdos, a universalidade da própria forma mercadoria.

Os estudos sobre indústria cultural no Brasil se confundem com a própria história da recepção da Teoria Crítica da Escola de Frankfurt aqui nos trópicos. Conforme Renato Ortiz (1988) em conhecido trabalho, a consolidação de uma indústria cultural no país ocorreu tardiamente, mas sua existência despertou o interesse de vários pesquisadores durante a década de 1970. Desde então, embora em uma proporção bem menor do que revelaria a importância do tema, alguns estudos, sobretudo empíricos, foram feitos sobre indústria cultural no Brasil, predominando investigações quanto ao papel da televisão em nosso cenário cultural e sua importância na realidade nacional (KEHL, 1979; FREITAG, 1989; HAMBURGUER, 2002; RAMOS, 2004).

O cinema, a televisão e a indústria fonográfica, sempre estiveram, desde a criação do conceito de indústria cultural, no centro das reflexões e mesmo dos estudos empíricos acerca do processo de transformação da cultura em mercadoria em moldes bastante 
específicos do capitalismo tardio. Se no próprio conceito de indústria cultural $^{9}$ tais fenômenos aparecem como exemplificação do fenômeno histórico da cultura de massas, também os poucos estudos existentes no Brasil sobre a indústria cultural historicamente enfatizam principalmente o fenômeno da televisão. Temos visto, desde os anos 1970, incursões em temáticas como a da telenovela, provavelmente em decorrência da especificidade que esta passou a evidenciar enquanto um bem cultural cujo significado mercadológico continua a ser reconhecido pelos estudiosos do campo da comunicação (HAMBURGUER, 2005; 2011) como um dos mais significativos produtos lucrativos na cultura e na economia brasileiras.

Poucos estudos estritamente sociológicos existem sobre transformações ocorridas nos três ramos acima mencionados no período de passagem dos anos 1990 aos anos 2000. No caso específico da televisão, curiosamente o destaque da importância de tais transformações da indústria cultural para investigações em sociologia apareceu recentemente com maior ênfase em autores de fora do Brasil (LASH \& LURY, 2007; FOX, 1997; FOX \& WAISBORD, 2002; HESMONDHALGH, 2007). Cabe ainda destacar que se o interesse pelo conceito e pelo fenômeno da indústria cultural sempre foi um pouco marginal entre os estudiosos da cultura no país, por outro lado, os pesquisadores que têm como núcleo de suas reflexões as transformações tecnológicas recentes, incluindo a internet (COHN, 2009; RUDIGER, 2013), em sua maioria sequer mencionam ou levam em consideração o conceito de indústria cultural, visto que a matriz teórica que tornou tal conceito possivel, a análise marxiana da mercadoria e seu fetiche, cedeu espaço para outras tradições epistemológicas, como é o caso do pós-estruturalismo francês ou

9 É preciso destacar que uso a expressão "conceito de indústria cultural" para fazer referência ao como este é desenvolvido por Adorno e Horkheimer especialmente na Dialética do Esclarecimento. Entendemos que os ingleses Scott Lash (2007) e Hesmondhalgh (2007), por exemplo, se pautam por um entendimento da noção de indústria cultural bastante distinta da tradição frankfurtiana, o que fica claro na exposição feita pelos autores onde a expressão predominantemente utilizada é "indústrias culturais" no plural, para diferenciar de "indústria cultural". 
mesmo dos que se aproximam ao conceito de capitalismo cognitivo (COCCO et. al., 2003; CAMARGO, 2010).

As diversas matrizes teóricas que embasam distanciamentos ao conceito de indústria cultural podem ser agrupadas, com certo perdão pelo reducionismo, quanto ao otimismo ou pessimismo acerca do processo histórico. A compreensão de que as ideias de Adorno e Horkheimer tendem a um olhar pessimista da história já se constitui tão impregnada de um senso comum acadêmico que até os que discordam dessa visão a usam para fins de exposição. Apenas dois exemplos: aqueles que de algum modo se aproximam do pensamento de Jürgen Habermas e sua teoria da ação bidimensional (HABERMAS, 1987), reivindicam a existência de uma esfera pública onde a ação comunicativa pode se evidenciar, como no campo da cultura, enquanto forma de contraposição aos ditames ideológicos da indústria cultural. Assim, para darmos um exemplo genérico, uma telenovela ou filme produzido pela "Globo Filmes", poderia trazer elementos críticos e reflexivos, sendo esta, por exemplo, a visão do sociólogo brasileiro Sérgio Costa (2002). Em outra vertente teórica, mais recente, assumida por parte dos que pensam sobre o fenômeno da internet, estariamos em um contexto em que o conhecimento e o saber, passivel de ser compartilhado em rede, desafia o próprio conceito de propriedade privada, e mais do que isso, a possibilidade de troca, criação e multiplicação de informações possibilitariam que formas criativas de produção cultural surgissem em um espaço totalmente outro do que aquele da indústria cultural (CORSANI et. al., 1996), sendo esta uma visão predominante entre os defensores em âmbito internacional do conceito de capitalismo cognitivo (MOULIER-BOUTANG, 2007).

Apenas para ficarmos com esses dois exemplos de olhares para o campo dos bens culturais, que pouco se interessam pelo conceito de indústria cultural, e que não são olhares exclusivamente de sociólogos brasileiros, destaca-se em meu entendimento uma recusa de tentar compreender transformações no cenário cultural brasileiro tomando-se como parâmetro a relação entre a histórica da indústria cultural do país 
e o advento relativamente recente da internet. Nas duas últimas décadas, ou um pouco mais, os processos de produção de sonoridades e imagens no país têm se transformado rapidamente, acompanhando as transformações planetárias (CASTELLS, 2003). Em princípio, hoje qualquer cidadão pode produzir um filme, ou conjunto organizado de imagens, e postar sua produção no YouTube. Seja com um smartphone ou com câmeras digitais cada vez mais acessiveis a um público não especializado, podemos compartilhar tal produção com milhões de pessoas. Em meu entendimento temos aqui um fenômeno não visualizado em seus desdobramentos históricos pelos criadores do conceito de indústria cultural. Estariamos hoje, cabe perguntar, frente a um cenário em que as teses de Adorno e Horkheimer já não tem validade em detrimento de um panorama histórico que vai além do que eles presenciaram? E já que ambos são comumente também chamados de elitistas e eurocêntricos pensemos sobre a pergunta acima nos atendo ao tropical cenário brasileiro.

\section{III}

Se, por um lado, alguns estudos sobre a televisão no Brasil, especialmente antes dos anos 1990, recorreram ao conceito de indústria cultural, por outro lado, poucas análises sobre o cinema brasileiro empreenderam este mesmo tipo de análise sociológica. Ao contrário, muitas análises tendem a fazer uma elegia das transformações positivas ocorridas no cenário cinematográfico posteriores a 1995, em geral associadas ao já conhecido debate sobre o cinema da retomada (CAETANO, 2005). Enquanto que temos um conjunto qualitativo de elementos para pensarmos a relação entre Estado e Cultura no período de 1995 a 2005, principalmente quanto ao papel decisivo das leis de incentivo à cultura (RUBIM \& BARBALHO, 2007), entendemos que se naturalizou tratar o cinema como ramo da indústria cultural, como algo evidente por si, tratando-se de uma indústria como outra qualquer, como se falar de cinema fosse o mesmo que falar de automóveis ou sabonetes. Cabe ainda lembrar, a escassez 
de críticas sobre o conteúdo ideológico dos filmes produzidos e exibidos no período, alguns deles com repercussão fora do Brasil, havendo quanto isso raras exceções, como é o caso de Ivana Bentes (2007).

A constatação de que a partir de 1995 o cinema brasileiro passa a renascer das cinzas traz consigo uma série de questionamentos, nem sempre lembrados, sobre a conexão entre cinema e relações sociais capitalistas. Ocorre que a naturalização do mercado, como afirmação do neoliberalismo, também se evidencia no campo cultural. Contudo, o mercado, como a esfera em que se processa a circulação de mercadorias, inclusive a cultural, não explica por si a própria produção dessas mercadorias, que em última instância continuam a se dar no âmbito de relações sociais nem tão distintas daquelas do sec. XIX. Aliás, o caso do cinema é bastante sugestivo quanto à história do capitalismo no Brasil: alguns entendem que o cinema brasileiro jamais teve uma estrutura industrial, como aquela hollywoodiana criticada por Adorno e Horkheimer, portanto, dificilmente adequado ao conceito de indústria (HAMBURGUER, 2002, p. 44), e no outro extremo, poderiamos dizer que pudemos dispor, recentemente, de alguns recursos tecnológicos e de organização da produção, bastante típicos de uma sociedade pós-industrial, como iremos argumentar adiante.

Se considerarmos apenas o aspecto da produção de filmes, devemos levar em conta que os recursos oriundos das leis de incentivo à cultura também possibilitaram a modernização do aparato tecnológico, que coloca alguns filmes do período em um nível bastante qualificado de produção técnica, referendando o próprio desejo de muitos cineastas de fazerem filmes com qualidade de circulação internacional. As transformações da mídia evidentemente se refletem não apenas na produção cinematográfica nacional, mas no advento de novas formas de produção e circulação de imagens que já haviam iniciado na década de 1990. Assim, destacam-se algumas características do período: a) a propagação da TV a Cabo, com emissoras como HBO, passou a ampliar o leque de possibilidades aos consumidores de filmes; b) consolidou-se a quase exclusividade de salas 
de cinema em Shopping Centers; c) passaram a ser produzidos filmes de curta e longa metragem, contraditoriamente, com características não comercias; d) a internet passou crescentemente a ampliar as formas de comunicação e divulgação da produção cinematográfica (LASH \& LURY, 2007).

Fato já destacado por estudiosos do chamado cinema da retomada é a ambiguidade quanto à produção de filmes brasileiros com média de público expressiva como são os casos (entre 2000 e 2005) de "2 Filhos de Francisco", "Carandiru", "Cidade de Deus" e "Olga" de um lado, e de outro lado, várias dezenas de filmes que jamais chegaram às telas dos cinemas, ou que tiveram uma bilheteria bastante irrelevante como são os casos de "Cabra Cega", "Cama de Gato" e "Latitude Zero" (OCA, 2016). Se investimentos foram feitos em grandes e em pequenas produções, uma das curiosidades está justamente nas expectativas de retorno que teriam se colocado sobre as últimas. Expectativas do ponto de vista do mercado, isto é, se uma determinada produção terá efetivamente bilheteria, como do ponto de vista do próprio cineasta, que deveria ter o natural interesse de que algum tipo de público venha a ver seu filme, senão o grande público, das grandes produções, algum outro tipo de público. Em ambos os casos, cabe lembrar, estamos falando de produções feitas com leis de incentivo à cultura (CAETANO, 2005).

Se ainda não tínhamos, até 2005, uma ampla popularização das câmeras digitais e smartphones atualmente massificados, e o fenômeno do YouTube ainda sequer existia, visualizamos já um processo de transição do modelo clássico da indústria cultural, no que se refere às imagens, para outro modelo em que a forma de produção e circulação de imagens se alterou em diferentes aspectos. Esta modificação na produção já vinha se consolidando no cenário internacional desde a década de 1980. A superação do texto pela imagem, como uma nova forma de narrativa, já havia sido apontada por Fredric Jameson (1997) em sua caracterização da pós-modernidade. Não por acaso, o vídeo ocupa um lugar central na análise do crítico cultural norte-americano. Diferente dos filmes de longa-metragem, o vídeo representa uma nova 
temporalidade que aponta para algo novo no contexto das próprias transformações globais da indústria cultural.

Por outro lado, no caso específico do cinema brasileiro, o curioso é que aqueles mesmos filmes de grande público e orçamento continuaram a abordar temas típicos de momentos anteriores da cultura nacional, como é o caso da necessidade incessante de retratar o que se chamava de identidade nacional, tema recorrente em momentos anteriores da história do cinema nacional. Basta mencionamos os quatro filmes mencionados acima, de grande bilheteria. Mas, falar do Brasil e de suas mazelas, provavelmente perdeu a tentativa de crítica e autocrítica que o cinema inspirado em Glauber Rocha tentara fazer. O romantismo revolucionário destacado por Marcelo Ridenti (2001) cedeu espaço a um processo de completa mercantilização, não obstante suas ambiguidades. Mais uma vez, portanto, o diagnóstico cultural de Jameson (1998) cobra sentido, pois afinal de contas economia e cultura se fundiram por completo, pouco restando às utopias externas à lógica da mercadoria.

Falar sobre o Brasil sempre foi, também, dispor de uma mercadoria com alto potencial de valor de troca, fato já sugerido mais de uma vez por Roberto Schwarz (1978; 2012). O que possivelmente diferencie, em certa medida, este cinema recente daquele oriundo ainda dos anos 1960, é que o ímpeto transformador de artistas e agentes culturais seja cada vez menos visivel enquanto uma crítica da própria mercadoria. Esta se naturalizou como o próprio modelo econômico que a contextualiza. O pragmatismo político é também a racionalidade instrumental de uma imensa parte dos que fazem cinema: o resultado esperado é em geral acompanhado de alguma expectativa de um resultado monetário. Mas o contraditório é que este resultado não veio para muitos, se consideramos a quase totalidade dos filmes produzidos nesses seis anos que analisamos. Dinheiro público foi investido, e não pouco, em filmes que ninguém viu. Falarmos sobre as dificuldades de distribuição e exibição, e das salas de cinema no Brasil é apenas um 
dos aspectos envolvidos nessa ambiguidade, onde de resto algumas poucas empresas souberam lucrar.

Não obstante o crescimento da produção de documentários e filmes independentes, num cenário de distribuição homogeneizado pela "Globo Filmes", o que resta perguntar é onde estaria o cinema com intenção e potencial político transformador das condições históricas. A naturalização da indústria cultural e de seu conceito é paralela à naturalização da exposição nas telas de temas como o presídio, a favela, a corrupção policial e das instituições. Pouco espaço há no cinema pós anos 2000 para a efetivação do sonho brechtiano de chocar as massas. Estas, aliás, estão mais ocupadas em espiar as atrocidades do "Big Brother Brasil" (VIANA, 2013), do que em gastarem seu dinheiro nas salas de cinema, em sua maioria situadas em Shopping Centers.

IV

Se no cinema a estética da violência ou a narrativa da fome buscam apreender os temas aparentemente candentes da realidade nacional, esta última também se insinua nos enredos de algumas telenovelas do período. Antes de chegarmos a elas e a televisão, expressão maior e ainda não superada da indústria cultural no Brasil, cabe lembrar que a partir desse período os videogames encontraram no Brasil um de seus grandes públicos consumidores no mundo. Com ou sem o uso de computadores, os videogames passaram a disputar a experiência social do tempo livre de uma parte dos brasileiros, sobretudo adolescentes (NEWZOO, 2015). Assistir ao seriado Malhação no fim de tarde da Rede Globo já não é mais alternativa única do não pensar do entretenimento. A propagação das Lan Houses nesse momento histórico expressou o crescimento, mesmo que lento, da internet no Brasil. ${ }^{10}$ Mas, aponta também para a potencial dubiedade

10 Dados indicam que até 2005 a internet ainda não está plenamente popularizada no Brasil, sendo ainda algo acessivel para as camadas médias da população (FSP, 2016). Trata-se, portanto, de um momento de transição (2000-2005) no que se refere a termos nos lares brasileiros o computador como concorrente da televisão. A participação do público na formatação do bem televiso, continua a se dar, por exemplo, mediante mecanismos como o SMS e o telefone. O mesmo vale para o cinema: não havia ainda, até 2005 , uma plena utilização da 
da indústria cultural na era das redes, visto que o instrumento de comunicação é também atinente ao lazer, às opções de uso do tempo livre e de não trabalho. Se a televisão continua a ter um predomínio, passa a conviver, ao mesmo tempo, com novos ramos da indústria do entretenimento, cujo caminho, desde então, tem sido o de uma proeminência da internet na sociabilidade humana, considerando seus vários aspectos: do trabalho ao não trabalho.

Lash \& Lury (2007) apontam que a propagação da TV a Cabo no Brasil não chegou a alcançar a amplitude desejada, se mantendo como uma alternativa, naquele momento, para camadas estritas da população. Quem precisava pagar Lan Houses para procurar emprego ou se matricular na escola noturna provavelmente não dispunha de recursos monetários para pagar TV por assinatura. Por outro lado, as possibilidades de compra a crédito de uma economia crescentemente estabilizada ajudaram a ampliar o acesso a telefones celulares dotados de dispositivos de SMS, que tiveram um significado que não pode passar despercebido. Embora o acesso à internet de banda larga e a assinatura de pacotes de TV a Cabo tenha se mantido um privilégio das classes médias até 2005, houve no período, principalmente a partir de 2003, um significativo crescimento do comércio de computadores, telefones celulares e câmeras digitais (EARP e PAULANI, 2014, p. 474). As modificações econômicas que se processaram, sobretudo a partir do primeiro governo Lula, também tiveram incidência quanto ao crescimento da aquisição de bens direta ou indiretamente relacionados com a produção cultural no período.

Quando se faziam pesquisas sobre indústria cultural no Brasil dos anos 1970 a imagem do individuo sentado diante de uma telenovela era acompanhada, por exemplo, de uma casa onde o telefone fixo alcançava ainda uma parcela exígua da população. Não era tão simples

rede como forma de divulgação da produção cinematográfica ou de interação dos produtores com o público. 
pegar o telefone e ligar para um programa de auditório. Já no início dos anos 2000 o público espectador teve a possibilidade de opinar no primeiro "Survivor" produzido no Brasil ("No limite", exibido pela rede Globo), poucos anos depois esquecido no universo dos reality shows que passaram a ter vida longa na televisão brasileira. Basta lembramos que é nesse momento que tem início o "Big Brother Brasil", fenômeno duradouro na televisão brasileira. Através de telefones celulares o público passou a decidir sobre o espetáculo que está assistindo mediante formas de interação e comunicação antes improváveis. Os brasileiros, seguindo uma tendência de comportamento do público consumidor de bens culturais de outros países do mundo, passam a moldar a mercadoria que eles próprios consomem em seu tempo livre.

Enquanto que nos tempos do "Cassino do Chacrinha" na década de 1980 a plateia presente no auditório, previamente ensaiada, levantava cartõezinhos coloridos para decidir o desenlace de algum "vai para o trono ou não vai”, nos anos 2000 decide-se se Pedro ou Maria, com seus corpos esculturais, continuam ou não no programa de televisão através da participação direta de muitos milhões de espectadores. A indústria cultural, desde o seu início, e tendo seu marco ilustrativo os Estados Unidos dos anos 1940, sempre confeccionou seus produtos, fabricados sob o padrão fordista, levando em conta o gosto do público. Ela sempre realizou pesquisas, aplicou questionários, entrevistou pessoas de classes sociais distintas, etc., para lapidar o bem cultural, sobretudo músicas e filmes, a ofertar no mercado. Por outro lado, a relação entre produção cultural e o público, considerando-se os desejos deste quanto à mercadoria que ele próprio consome, não passou despercebido pelos frankfurtianos, em especial para Adorno durante seu exílio norte-americano (ADORNO, 1995b) onde ele realizou pesquisas empíricas sobre a relação entre produção e a atitude do consumidor na música e no rádio (ADORNO, 1994).

Para Adorno a indústria cultural não pode ser tomada como uma mera repetição da ideia de indústria (ADORNO, 1986b, p. 95), pois ela se refere igualmente ao processo de circulação, e principalmente, ao 
modo pelo qual no capitalismo se processa uma produção da consciência. Mas apontarmos para o fato de que os processos de produção e organização do trabalho que contextualizavam o período histórico de Adorno, isto é, o fordismo, já não corresponde mais aos atuais processos, não significa termos que abdicar da atualidade do conceito de indústria cultural quanto à sua essência, que é a reificação, mas as transformações em curso dizem respeito a um entendimento sobre a natureza do próprio processo de produção de valor e riqueza no capitalismo avançado. Em outras palavras, no capitalismo contemporâneo se modifica o papel da subjetividade na esfera do consumo. Embora me pareça plausivel uma posição como a de Wolfgang Leo Maar quando afirma, ao falar da atualidade de Adorno e da indústria cultural, que "o consumo constitui um momento do processo reprodutivo do capital" (MAAR, 2000, p. 16), o que estou me referindo, quanto a um contexto de advento do trabalho imaterial (CAMARGO, 2009) é que não há como pensarmos o tempo livre, do entretenimento, com base em uma premissa da ontologia do trabalho social.

Mas, voltando ao caso brasileiro, minha hipótese é de que nunca antes, como a partir dos anos $2000,{ }^{11}$ o consumidor atuou de uma forma tão direta e imediata sobre a mercadoria que está consumindo, especialmente no caso da televisão. Assim como em outros setores produtivos que embalaram para o caminho do pós-fordismo, o produto não está finalizado antes de certa atuação do consumidor. Há uma atividade adjacente à sua passividade. A reificação tal como postulada originariamente por Lukács (1986) encontra um novo momento, em que a passividade e a contemplação assumem o formato de certa atividade, não menos reificada e contemplativa (CAMARGO e SOUZA, 2012).

11 A suposição de um novo tipo de relação entre produção e consumo, que demarcaria uma nova etapa na história do capitalismo foi desenvolvida no livro Trabalho Imaterial e Produção Cultural (CAMARGO, 2009). Ali, tomando como ponto de partida os Grundrisse de Marx, desenvolvi a tese de que aquilo que Theodor W. Adorno chamou de capitalismo tardio assumiu outras conotações a partir da década de 1970, com implicações quanto à própria teoria do valor. Aqui neste artigo, estou buscando estender para a realidade brasileira argumentos teóricos já apresentados naquela e em outras publicações. 
Nunca foi tão fácil também saber sobre o gosto do público para o final da telenovela, cujo último capítulo depende dele. As possibilidades de apreensão do gosto do consumidor, ou, do público espectador em relação a uma determinada narrativa, se consolidaram de forma evidente nos anos 2000. São os próprios recursos tecnológicos e de comunicação que tornaram possivel ao autor de telenovela delinear o destino de seus personagens e de sua própria ficção. A apreensão das reações do público já não depende de questionários feitos com antigas metodologias de apreensão do gosto do público. As novas tecnologias de comunicação permitem que o autor de novela, sua equipe, produtores, e todos os envolvidos num aparato altamente lucrativo de produção deste bem cultural, influenciem o gosto do consumidor/espectador, mas ao mesmo tempo moldem sua mercadoria, isto é, sua narrativa ficcional, de acordo com as tendências apreensiveis numa determinada conjuntura social. Se a produção de telenovelas no Brasil nunca chegou a ter o rigor da produção fordista, então estamos falando de um fato relativamente singular de nossa indústria cultural, pois ela passa a lidar com uma característica do pós-fordismo, isto é, pelo papel codeterminante do consumidor quanto à mercadoria que ele próprio irá consumir (CORSANI et. al., 1996). No pós-fordismo o papel do consumidor é apreendido não só quanto ao tipo de automóvel que ele gostaria de ter, mas também quanto ao tipo de final de telenovela que realizaria seus desejos e expectativas de felicidade, agora condensada em um conjunto de imagens.

O crescimento da internet e o surgimento de novas formas de comunicação, informação e entretenimento, diferente do que se poderia imaginar, não diminuiu tão drasticamente o papel central ocupado pela televisão na indústria cultural brasileira. A televisão aberta continua a ser, até os dias atuais, o principal atrativo do "tempo livre" da maior parte da população brasileira, apesar do seu relativo declínio (BUCCI, 2000; BOLAÑO e BRITTOS, 2007). Se houve no período analisado o surgimento de multifacetadas formas de produção cultural nas periferias, com destaque para a música, ou como dissemos logo acima, 
o também crescimento de videogames, tais fenômenos se agregaram ao protagonismo da televisão na sociedade brasileira. Se a indústria cultural é também, como afirmaram Adorno e Horkheimer elemento de integração social, nenhum exemplo serve mais apropriadamente do que a televisão aberta no Brasil.

Entre 2000 e 2005 cinema e televisão no Brasil, como setores dos mais significativos da indústria cultural, expressaram continuidades e rupturas com momentos anteriores da história da indústria cultural no país em sentidos um pouco distintos. O cinema nacional, quanto à sua produção, manteve o padrão de crescimento, mediante as leis de incentivo fiscal iniciadas em 1995, mantendo igualmente os insolúveis problemas de distribuição. As novas tecnologias se manifestaram aqui principalmente quanto a uma ampliação e democratização que trouxe a possibilidade de se fazer filmes com baixo orçamento. Ao mesmo tempo, até 2005 ainda era tímido o papel da internet como forma de circulação de imagens. Cabe também destacar que as questões da identidade nacional permaneceram candentes, mas entendemos que em um registro diferente do cinema anterior aos anos 1990. Aqui, a mercantilização da imagem do país se naturalizou, ao mesmo tempo em que a televisão brasileira passou a competir com o fenômeno da internet, mas igualmente de forma tímida, pois mudanças mais substantivas somente ocorrem depois de 2005. A telenovela e a TV aberta continuam a ter um papel central na vida dos brasileiros e há como destaque o surgimento dos reality shows como programas de grande popularidade. Estes últimos evidenciam um fenômeno que considero novo: assim como outros produtos da televisão brasileira seu conteúdo e mecanismos de funcionamento expressam um novo tipo de relação entre produtor e consumidor. O modelo clássico da indústria cultural, fundado em simetria ao próprio desenvolvimento da produção industrial fordista, cede espaço a um modelo em que a subjetividade das massas, sua capacidade de interferir no conteúdo da mercadoria televisiva se torna evidente. A popularização dos telefones celulares e os mecanismos tecnológicos de interface entre produtor e consumidor dão 
início ao que entendemos ser um processo de transformação gradativa da indústria cultural no país.

\section{V}

Se o rádio representou entre os anos 1940 e 1980 um ramo significativo da indústria cultural no Brasil, há que considerarmos que o seu papel se modifica também a partir do crescimento da internet, visto que esta possibilitou modificações substantivas quanto à indústria fonográfica e a produção de sonoridades com finalidade comercial. A possibilidade de disponibilização de músicas na internet popularizou-se antes do que as imagens, enquanto que e a lucratividade do ramo musical migrou para outros formatos para continuar existindo. Ao mesmo tempo, o início dos anos 2000 viu surgir a indústria de jogos eletrônicos como ramo de forte impacto econômico quanto à produção de bens culturais. Embora tais jogos em sua maioria sejam produzidos fora do Brasil, e os dados do setor sejam ainda hoje de dificil acesso, foi também com a introdução da internet de banda larga que os chamados videogames passaram a ocupar um papel crescente no tempo livre das massas. O Brasil é um dos maiores mercados mundiais de consumo de tais jogos (NEWZOO, 2015). Devemos destacar ainda que as revistas impressas, tão importantes na indústria cultural brasileira dos anos 1970, foram cedendo espaço para as revistas on-line, alterando a forma de funcionamento de um setor clássico da indústria cultural nacional.

O período de 2000 a 2005 representa, conforme minha hipótese nesse artigo, um momento de transição na história da indústria cultural no Brasil. Os setores clássicos desta indústria, principalmente quanto ao setor audiovisual e produtor de imagens, nos casos aqui enfatizados o cinema e a televisão, trazem algumas continuidades de características das três décadas anteriores, mas apontam tendencialmente para transformações que ficarão mais visíveis, em meu entendimento, em anos posteriores a 2005. Tais transformações dizem respeito principalmente à popularização da internet no Brasil e seu crescimento mundial. Por um lado, o papel da internet até 2005 ainda 
era tímido, notadamente quanto à sua relação com a indústria cinematográfica e ao campo de produção e circulação de imagens, por outro lado, já começamos a perceber uma tendência, melhor evidenciada nos anos subsequentes, de participação de grande parcela da população nas mercadorias culturais que ela própria consome. Há também um problema relativo ao tipo de subjetividade que alavanca os bens produzidos pela indústria cultural, incluindo-se o caso brasileiro. Ao invés de recorrermos ao conceito jamesoniano de pós-modernismo, sugerimos em outro lugar (CAMARGO, 2009) a ideia de uma pósindústria cultural.

O pós-moderno para Fredric Jameson expressava uma nova etapa do modo de produção capitalista, considerando-se ser o autor um dos poucos pensadores contemporâneos a propor explicitamente uma retomada do antigo conceito de totalidade de Adorno (JAMESON, 1996). ${ }^{12}$ A indústria cultural para Jameson faz referência a um dos aspectos da produção cultural contemporânea, sendo um conceito em parte superado pelo fato de que em sua concepção do capitalismo tardio as esferas da economia e da cultura se tornaram indistinguiveis, ao mesmo tempo em que não haveria mais no presente a velha distinção entre alta cultura e cultura de massas, uma das origens do conceito de indústria cultural. Cabe lembrar ainda que o cenário cultural predominantemente analisado por Jameson é o da cultura norteamericana dos anos 1980. Sem ter a pretensão de criar neologismos concorrentes com os diferentes "pós" inaugurados desde o final da década de 1970 na ciência social contemporânea, nos pareceu, em trabalhos anteriores, que se a indústria cultural não funciona mais como uma indústria, também ela reflete as formas de produção já presentes em outros setores da produção de mercadorias, no caso, por exemplo, da Sociologia do Trabalho, em que hoje é amplamente reconhecida a expressão pós-fordismo. Embora o prefixo “pós” seja

12 Acerca da importância do conceito de totalidade para a teoria da sociedade adorniana e de suas diferenças e aproximações com Lukács, além do livro de Jameson, debati extensamente este tema no livro Modernidade e Dominação (CAMARGO, 2006) especialmente nos capítulos 1 e 4. Sobre este debate também é possivel consultarmos Martin Jay (1984) e Moishe Postone (2003). 
polêmico e hoje pouco simpático para amplos setores das ciências humanas, ele traz um tom provocativo e provisório: aponta para o fato de que o antigo conceito, no caso o de "indústria cultural", já não corresponde perfeitamente ao que se processa na realidade histórica. Entendemos que está ocorrendo um processo de transformação quanto à produção e circulação de bens culturais e uma modificação quanto à relação entre produtor e consumidor, cujo melhor exemplo empírico, nos limites que pude traçar neste artigo, é o da televisão brasileira. Ocorre que, não obstante tais transformações, meu entendimento é de que os antigos conceitos de reificação e razão instrumental (ADORNO e HORKHEIMER, 1985) nucleares do conceito de indústria cultural, continuam presentes e atuais na forma de uma consciência e de uma integração social que apontam para o obscurecimento da formação de indivíduos portadores de autonomia e reflexividade, tal como havia sido o projeto moderno da Aufklärung.

Voltemos aqui a dois modelos, entre outros anteriormente esboçados, de crítica ao conceito de indústria cultural. Por um lado, os pesquisadores do campo da cultura digital (COHN e SAVAZONI, 2009) costumam destacar os aspectos positivos e mesmo potencialmente progressistas que a internet tem possibilitado desde o seu surgimento. Uma das razões para isso está no fato de que a liberdade de circulação de imagens e sonoridades pela rede tenderia a minar em sua própria base inclusive a noção de propriedade (BARBROOK, 2003). De outro lado, há o modelo apresentado pelos próprios seguidores da Teoria Crítica, em especial os habermasianos, que reivindicam que o conceito de indústria cultural estaria fundado em uma concepção estreita de razão instrumental, negligenciando ambivalências existentes no campo da cultura e da esfera pública (COSTA, 2002; AVRITZER e COSTA, 2004). Ambas as vertentes opositoras ao conceito de indústria cultural poderão reivindicar ainda, como traço comum entre elas, o advento de uma cultura de periferia, justamente neste marco histórico aqui analisado, como a expressão de mecanismos de contraposição ao sistema da indústria cultural. A consolidação do Rap, de uma literatura 
de periferia e mesmo de produção de vídeos independentes, entremeadas com as possibilidades de compartilhamento em rede (HOLLANDA, 2012), apontaria para as limitações de um conceito que apreende a universalidade da forma mercadoria no conjunto da produção cultural moderna, mesmo após o fim do alto modernismo estético.

A hipótese que defendo nesse artigo adota um caminho distinto. A atualidade do conceito de indústria cultural se ancora em uma teoria da dominação social que tem como epicentro a herança do que alguns chamam de filosofia do sujeito, em especial a compreensão adorniana de dialética negativa, que com base em uma concepção de primazia do objeto (ADORNO, 1984) se ocupa acima de tudo com aquilo que se passa no âmbito da consciência dos indivíduos em sua relação com o modo de produção capitalista. Sustentamos que, com base em tal concepção, são inegáveis transformações no capitalismo mundial a partir de 1970, fazendo com que a indústria cultural esteja migrando de um antigo modelo para um novo, em que a posição do sujeito, ou da subjetividade, está se alterando quanto aos seus mecanismos de funcionamento. As modificações recentes no setor de produção audiovisual no Brasil exemplificam empiricamente tais mudanças, em especial a produção televisiva, mas ao mesmo tempo referendam a continuidade do que caracteriza o antigo conceito de indústria cultural: a preponderância da reificação e da razão instrumental no chamado tempo livre das massas.

Concordo com a percepção de que experiências culturais variadas permeiam a realidade brasileira, em suas diferentes classes e estratos sociais, mas nunca é demasiado lembrar que o conceito de indústria cultural cunhado por Adorno e Horkheimer se fundava em outro, presente na Dialética do Esclarecimento que é o "conceito de esclarecimento", e neste se evidencia que a dominação capitalista só se tornou possivel quando adentrou a subjetividade dos individuos. Certamente estamos todos em rede e compartilhando. Cabe apenas perguntar que tipo de música, imagem e experiência social estão as 
massas, e nós todos, compartilhando em nossas páginas do Facebook. Embora pouco estudada pela Sociologia Brasileira a indústria cultural, conforme entendo, está no epicentro das formas de dominação social que caracterizam a sociedade e o capitalismo brasileiro mesmo em sua formação periférica, e em última instância, me parece que a questão fundamental quanto à importância ou não de um conceito tão antigo como o de indústria cultural está em reconhecer a existência ou não de relações sociais permeadas por poder e dominação.

\section{BIBLIOGRAFIA}

ADORNO, Theodor. O Fetichismo na Música e a Regressão na Audição. São Paulo: Abril: 1983.

Dialética Negativa: Madrid: Taurus, 1984.

Capitalismo Tardio ou Sociedade Industrial? In: COHN, Gabriel (Org.). Sociologia. São Paulo: Ática: 1986a.

A indústria cultural. In: COHN, Gabriel. Theodor W. Adorno Sociologia. São Paulo: Ática; pp. 92-99, 1986b.

Educação e Emancipação: Rio de Janeiro: Paz e Terra: 1995a.

Experiências científicas nos Estados Unidos. In. ADORNO, Theodor W.. Palavras e Sinais. Modelos Criticos 2. Petrópolis: Vozes: pp. 137-178; 1995b.

Analytical study of the NBC music appreciation hour. The Musical Quarterly. Oxford, vol. 78, n.2; pp. 326-377; 1994.

. Moda Intemporal - sobre o jazz. In: Prismas: crítica cultural e sociedade. São Paulo: Ática; pp. 117-130, 1998

. Televisão, consciência e indústria cultural. In: COHN, Gabriel (org.). Comunicação e Indústria Cultural. São Paulo: T. A. Queiroz; pp. 346-55, 1987.

. La Televisión como ideologia. In: Intervenciones: Nuevo modelo de crítica. Caracas: Monte Ávila; pp. 75-89, 1969.

. Transparencies on Film. New German Critique. N. 24/25; pp. 199-205, 1982.

As estrelas descem à terra. São Paulo: Unesp, 2007.

\& HORKHEIMER, Max. Dialética do Esclarecimento: Rio de Janeiro: Zahar, 1985.

AVRITZER, Leonardo e COSTA, Sérgio. Teoria Crítica, Democracia e Esfera Pública: Concepções e Usos na América Latina: Dados, vol. 47, $\mathrm{n}^{\circ} 4$, pp. 703-728, 2004. 
BARBROOK, Richard. A regulamentação da liberdade: liberdade de expressão, liberdade de comércio e liberdade de dádiva na rede. In: COCCO, G; GALVÃO, A.P; SILVA, C. (Orgs). Capitalismo Cognitivo: Rio de Janeiro: DP \& A. p. 133-150, 2003.

BENTES, Ivana. Sertões e favelas no cinema brasileiro contemporâneo. Alceu, vo. 8, n. 15, pp. 242-255, 2007.

BEST, Steven \& KELLNER, Douglas. The Postmodern Adventure: London: Routledge, 2001.

BOLAÑO, César Ricardo Siqueira e BRITTOS, Valério Cruz. A Televisão brasileira na Era Digital: São Paulo: Paulus, 2007.

BOURDIEU, Pierre. O Poder Simbólico: Rio de Janeiro: Bertrand Brasil, 2000.

O Senso Prático: Petrópolis: Vozes, 2009.

BUCCI, Eugenio (org.). TV aos 50 - criticando a televisão brasileira no seu cinqüentenário. São Paulo: Editora Fundação Perseu Abramo, 2000.

CAETANO, Daniel (Org.). Cinema Brasileiro 1995-2005. Rio de Janeiro: Azougue, 2005.

CAMARGO, Sílvio. Modernidade e Dominação: Theodor Adorno e a Teoria Social Contemporânea. São Paulo: Annablume/Fapesp: 2006.

. Trabalho Imaterial e Produção Cultural: a dialética do capitalismo tardio. São Paulo: Annablume: 2009.

.Trabalho Imaterial, cultura e dominação. Liinc em Revista, vol. 6, n. 1, pp. 6-21, 2010.

Itinerários da teoria crítica na sociologia brasileira. In: SILVA, J. P. (org.). Sociologia critica no Brasil. São Paulo: Annablume; pp. 155$86,2012$.

. Os primeiros anos da Escola de Frankfurt no Brasil. Lua Nova, vol. 91; pp. 105-133, 2014.

. Nota sobre Theodor Adorno na Sociologia Brasileira. In: ZUIN,

Álvaro Soares; LASTÓRIA, Luiz Antônio Calmon Nabubo; FRANCO, Renato (Orgs.). Teoria Critica no Brasil e na América Latina. São Paulo: Nankin; pp. 175-188, 2016.

e SOUZA. Axel Honneth leitor de Lukács: reificação e reconhecimento. Pensamento Plural, n. 11, julho-dezembro; pp. 165186, 2012.

CARVALHO, Marcelo Sávio Revoredo de. A Trajetória da Internet no Brasil: do surgimento das redes de computadores à instituição dos mecanismos de Governança. (Dissertação de Mestrado). Rio de Janeiro, 
Universidade Federal do Rio de Janeiro, Engenharia de Sistemas de Computação. 259 págs., 2006.

CASTELLS, Manuel. A galáxia da internet: reflexões sobre a internet, os negócios e a sociedade: Rio de Janeiro: Zahar, 2003.

COCCO, G; GAlVÃO, A.P; SIlVA, C. (Orgs.). Capitalismo Cognitivo. Rio de Janeiro: DP \& A, 2003.

COHN, Gabriel. Comunicação e indústria cultura: São Paulo: Companhia Editora Nacional/Edusp, 1971.

Pioneira, 1973.

Sociologia da Comunicação: Teoria e Ideologia: São Paulo: Difícil Reconciliação: Adorno e a Dialética da Cultura. Lua Nova, n. 20, pp. 5-18, 1990.

Esclarecimento e Ofuscação: Adorno \& Horkheimer Hoje. Lua Nova, n. 43; p. 5-24, 1998 a.

A atualidade do conceito de indústria cultural. In: MOREIRA, Alberto da Silva (Org.). Sociedade Global. Cultura e Religião: Petrópolis: Vozes, 1998 b.

COHN, Sergio e SAVAZONI, Rodrigo (Orgs.). Cultura Digital.br.: São Paulo: Azougue, 2009.

Comitê Gestor da Internet no Brasil (CGI). Dimensões e características da WEB brasileira: um estudo do. gov.br. 2010. 2016 a. Disponivel em: http:/ /www.cgi.br/. (Acesso em: 18/01/2016).

A próxima WEB: o que esperar do futuro da internet. Revista.br. Ano 2, edição 02. 2010, 2016 b. Disponível em: http://www.cgi.br/. (Acesso em: em 18/01/2016).

TIC domicílios e empresas 2011. Pesquisa sobre o uso das tecnologias de informação e comunicação no Brasil. 2010, 2016 c, 608 pgs. Disponivel em : http://www.cgi.br/. (Acesso em: 20/01/2016).

CORSANI, A.; LAZZARATO, M; NEGRI, A. . Le Bassin du travail immateriel (BTI) dans la Metrópole Parisienne. Paris: L'Harmattan, 1996.

COSTA, Sérgio. As Cores de Ercilia. Belo Horizonte: Editora UFMG, 2002.

DEBORD, Guy. The Society of Spetacle: London: Rebel Press, 1992.

DIAS, Márcia Tosta. Os Donos da Voz: indústria fonográfica brasileira e mundialização da cultura: São Paulo: Boitempo, 2000. 
DURÃO, Fábio Ackelrud; ZUIN, Antonio; VAZ, Alexandre Fernandes (Orgs.). A Indústria Cultural Hoje: São Paulo: Boitempo, 2008.

DUARTE, Rodrigo. A Teoria Critica da Indústria Cultural: Belo Horizonte: ed. UFMG, 2008.

A industria cultural 2.0. Constelaciones - Revista de Teoria Critica. n. 3/Dez. pp. 90-117, 2011.

EARP, Fábio de Sá e PAULANI, Leda Maria. Mudanças no consumo de bens culturais no Brasil após a estabilização da moeda. Nova Economia. N. 24 (3); pp. 469-490. Set/Dez. 2014.

20 anos de internet no Brasil (Caderno Especial). Folha de São Paulo (FSP). Disponivel em: http://temas.folha.uol.com.br/20-anos-dainternet/o-inicio/do-dial-up-ao-4g.shtml. (Acesso em: 15/01/2016).

FOX, Elizabeth. Latin America Broadcasting: From Tango to Telenovela. Luton: Luton University Press, 1997.

\& WAISBORD, Silvio (Editors). Latin Politics, Global Media: Austin: University of Texas Press, 2002.

HABERMAS, Jürgen. Teoria de La Acción Comunicativa. Tomo I "Racionalidad de la acción y racionalizacion social": Taurus: Madrid, 1987 a.

Teoria de La Acción Comunicativa. Tomo II - "Crítica de la razón funcionalista". Taurus: Madrid, 1987 b.

HAMBURGUER, Esther I.. Indústria Cultural Brasileira (Vista Daqui e de fora). In: MICELI, Sergio (Org.). O que ler na ciência social brasileira 1970-2002. São Paulo: editora Sumaré: pp. 53-84, 2002.

.O Brasil antenado: a sociedade da novela. Rio de Janeiro: Zahar, 2005.

.Telenovela em três tempos. In: BOTELHO, André \& SCHWARCZ, Lilian Moritz (Orgs.). Agenda Brasileira: São Paulo: Companhia das Letras: pp. 518-529, 2011.

HESMONDHALGH, David. The Cultural Industries: London: Sage, 2007.

HOLlANDA, Heloísa Buarque de. Cultura como Recurso: Salvador: Secretaria de Cultura do Estado da Bahia, 2012.

HONNETH, Axel. The Critique of Power. Reflective Stages in a Critical Social Theory: London: The MIT Press, 1991. 
HULLOT-KENTOR, Robert. El sentido exacto em el que ya no existe La industria cultural. Constelaciones - Revista de Teoria Critica. n. 3, deciembre, pp. 3-23, 2011.

JAMESON, Fredric. O Marxismo Tardio. Adorno ou a persistência da dialética. São Paulo: UNESP, 1996.

Pós-Modernismo. A Lógica Cultural do Capitalismo Tardio: São Paulo: Ática, 1997.

The Cultural Turn. London: Verso, 1998.

JAY, Martin. Marxism and Totality. Berkeley: University of California Press, 1984.

KEHL, Maria Rita. Anos 70: televisão: Rio de Janeiro: Europa, 1979.

LASH, Scott \& LURY, Celia. Global Culture Industry: Cambridge: Polity Press, 2007.

LÉVY, Pierre. A Inteligência Coletiva: São Paulo: Loyola, 2007.

Cibercultura: São Paulo: Ed. 34, 1999.

LUKÁCS, Georg. História e Consciência de Classe. Lisboa: Escorpião, 1986.

MAAR, Wolfgang Leo. A produção da sociedade pela indústria cultural. Revista Olhar. Ano 2; n. 3. pp. 1-24; 2000.

MARX, Karl. O Capital. Vol. I.: São Paulo: Boitempo, 2013.

MATTERLART, Armand e MATTERLART, Michele. O carnaval das imagens: São Paulo: Brasiliense, 1990.

MOULIER-BOUTANG, Yann. Le Capitalism Cognitif : Paris: Éditions Amsterdam, 2007.

NEWZOO, 2015. Disponivel em: <http://www.newzoo.com/news/threenew-infographics-on-russia-brazil-and-

australia/\#uQI4cFJwexDv6YPF.99>. (Acesso em: 10/11/2016).

Observatório Brasileiro do Cinema e do Audiovisual (OCA). Disponivel em: http://oca.ancine.gov.br/. Diversos acessos desde janeiro de 2016.

ORTIZ, Renato. A Moderna Tradição Brasileira: São Paulo: Brasiliense, 1988.

Mundialização da Cultura: São Paulo: Brasiliense, 1994. 
POSTONE, Moishe. Lukács and the dialectical critique of capitalism. In: ALBRITTON, Robert \& SIMOULIDIS, John (eds.). New dialectics and political economy. New York: Palgrave Macmillian; pp. 78-100, 2003.

RAMOS, José Mário Ortiz. Cinema, televisão e publicidade. Cultura popular de massa no Brasil dos anos 1970-1980. São Paulo: Annablume, 2004.

RIDENTI, Marcelo. Intelectuais e romantismo revolucionário. São Paulo em Perspectiva, vol. 15, n. 2, pp. 13-19, 2001.

Indústria cultural: da era do rádio à era da informática no Brasil. In: BOTELHO, André \& SCHWARCZ, Lilian Moritz (Orgs.). Agenda Brasileira: São Paulo: Companhia das Letras, pp. 292-300, 2011.

RUDIGER, Francisco. As teorias da cibercultura: Porto Alegre: Sulina, 2013.

ROCHA, Maria Eduarda. Em busca e um ponto cego: notas sobre a sociologia da cultura no Brasil e a diluição da mídia como objeto sociológico. Sociedade e Estado, vol. 26, n. 3, pp. 453-459, 2011.

RUBIM, Antonio Albino Canelas \& BARBALHO, Alexandre. Politicas Culturais no Brasil: Salvador, EDUFBA, 2007.

SCHWARZ, Roberto. O pai de família e outros estudos: Rio de Janeiro: Paz e Terra, 1978.

. Um seminário sobre Marx. Novos Estudos Cebrap, n. 50. pp. 99-113, 1998.

2012.

Martinha versus Lucrécia: São Paulo: Companhia das Letras,

TÜRCKE, Christoph. Sociedade Excitada. Filosofia da Sensação. Campinas: Editora da Unicamp, 2010.

VIANA, Silvia. Rituais de Sofrimento: São Paulo, Boitempo, 2013.

VOIROL, Olivier, Retour sur l'industrieculturelle. Réseaux, n. 166. pp. 125-157, 2011. 